\title{
Legitimidade e não legitimidade das experiências dos sofrimentos e adoecimentos de longa duração
}

\author{
Legitimacy and non-legitimacy of experiences \\ of long-term suffering and illness
}

\footnotetext{
${ }^{1}$ Departamento de Saúde Coletiva, Faculdade de Ciências Médicas, Universidade Estadual de Campinas. R. Tessália Vieira de Camargo 126, Barão Geraldo. 13089970 Campinas SP Brasil. anacanesqui@hotmail.com
}

\begin{abstract}
This paper discusses the legitimacy and non-legitimacy of selected experiences of longterm illness and suffering, which are, or are not, considered diseases by medical diagnoses, such as pain, chronic fatigue, and "high blood pressure" using international and national sociological and anthropological research in health. It explores their implications, reflexes and ambiguities for the identity, moral and physical suffering perceived by the subjects and in their relationship with others and with the health services. This is a text about select research on the theme. It concludes that the ill persons are moved by actions and significance about their experience with the physical and moral suffering that are, or are not, legitimate for them, but that jeopardize their lives and biographies, and are expressed in their language and emotions, reflected in their social relations and also in their identity of being, or not being, ill. The legitimacy and non-legitimacy of these experiences have implications for health care, which require further ethnographic research.
\end{abstract}

Key words Legitimacy, Non-legitimacy, Illness experience, Qualitative research
Resumo Discute-se a legitimidade e não legitimidade das experiências de adoecimentos e sofrimentos de longa duração selecionados, considerados ou não doenças pelos diagnósticos médicos, como a dor, a fadiga crônica e a "pressão alta", usando pesquisas internacionais e nacionais sociológicas e antropológicas em saúde. As análises dos relatos de adoecidos ou de profissionais de saúde nas pesquisas consideradas exploram o assunto, suas implicações, reflexos e ambiguidades geradas nos sujeitos e efeitos nas suas identidades, nos sofrimentos físicos e morais percebidos, na relação com os outros e com os serviços de saúde. O texto de natureza ensaística reflete e comenta estudos selecionados, concluindo que os adoecidos se movem por ações e significações sobre as experiências com sofrimentos físicos e morais, legítimos ou não para eles, mas que comprometem o cotidiano de suas vidas e biografias, expressos na linguagem $e$ nas emoções, refletidos nas relações sociais e nas identidades de ser ou não doente. O processo de legitimação e deslegitimação destas experiências trazem implicações para o cuidado em saúde, requerendo mais pesquisas etnográficas a respeito. Palavras-chave Legitimidade, Não legitimidade, Experiências da enfermidade, Pesquisas qualitativas 


\section{Introdução}

Deslegitimidade não se restringe à concepção de que certas síndromes, dores, fadiga crônica, entre outros adoecimentos e sofrimentos de longa duração, são considerados ou não doenças pelos diagnósticos médicos, mas que usufruem de status legitimado nas experiências dos adoecidos. Para Ware ${ }^{1}$ implica acatar e não somente desconsiderar as percepções e as interpretações das pessoas sobre estas experiências.

Estas experiências fogem dos parâmetros do enquadramento da doença pela biomedicina e, nestas condições, os adoecidos são estigmatizados e submetidos ao desconhecimento de sua vulnerabilidade ${ }^{1,2}$. Este tipo de discussão remete à realidade illness que para $\operatorname{Good}^{3}$ envolve a experiência típica e subjetiva dos adoecidos, tão presente nas suas vidas e comunicada através de um conjunto de palavras, de experiências e sentimentos associados, expressos nos networks de significados e nas relações sociais. Kleinman ${ }^{4}$ também destaca preocupações com o sofrimento como experiência moral em torno da dor crônica de difícil enquadramento pelos diagnósticos médicos.

A discussão do tema conduz a considerar o simbolismo e as implicações físicas e morais dos sofrimentos que acompanham muitas experiências legitimadas pelos que sofrem. Não é incomum deparar-se com adoecidos rotulados pejorativamente pelos profissionais de saúde de poliqueixosos, doentes irreais ou imaginários quando insistem e procuram respostas para os sofrimentos que os afligem, sem obtê-las.

Bury $^{5}$ lembra que a questão da legitimação envolve, também, o desejo das pessoas obterem controle sobre suas condições, buscando explanações que lhes façam sentido em relação às suas circunstâncias de vida e biografias. Se alguns processos de adoecimento provocam rupturas nas vidas dos adoecidos, o autor admite que a legitimação é um processo através do qual, se busca a credibilidade da autoridade e a manutenção do senso de integridade dos adoecidos diante de circunstâncias alteradas.

$\mathrm{Na}$ literatura internacional sobre doenças crônicas estão estudos sobre a legitimação/deslegitimação, constatados na revisão desta produção, no período 1980 a $2005^{6}$, nos periódicos de ciências sociais em saúde (Social Science and Medicine; Sociology of Health and Illness; Journal of Health andu Social Behaviour; Culture; Medicine and Psychiatry; Medical Anthropology Quartley; Qualitative Health Research e Anthropology and
Medicine). Os temas pesquisados foram: experiência da enfermidade; percepções e estratégias de ajustamento; perda do self; autoimagem e corpo; ruptura biográfica; gerenciamento da doença; modelos explicativos leigos e eruditos.

A literatura nacional, publicada nos periódicos de Saúde Pública/ Saúde Coletiva (artigos e resenhas de livros), na base eletrônica de informações Scielo, sobre as doenças crônicas, no período de 1997 a 2013 (junho) $)^{7}$, mostrou a forte presença da epidemiologia em $63,26 \%$ dos 98 artigos selecionados; $20,4 \%$ de ciências sociais e humanas e pesquisa qualitativa e o restante de políticas, gestão e planejamento, fazendo ou não interlocução com estas ciências. Os estudos deram-se a partir da segunda metade da década de 2000, sem ultrapassarem a magnitude dos estudos epidemiológicos, não havendo pesquisas sobre a experiência deslegitimada.

Este texto, de natureza ensaística, admite a importância de discutir as experiências legitimadas e não legitimadas pelos adoecidos a partir de exemplos extraídos de estudos internacionais e nacionais de ciências sociais em saúde. Dentre os últimos estão aqueles que, sem ter usado o conceito de deslegitimidade, permitem refletir sobre o assunto. Tomam-se como exemplos a fadiga crônica sem precisão diagnóstica e de sua etiologia, ao lado da dor crônica e da pressão alta (expressão do senso comum), consideradas patologias pela Medicina. Não se trata de rever a literatura sobre o assunto, mas de refletir sobre as implicações destas experiências para os adoecidos e o cuidado.

\section{Sobre a fadiga crônica}

Ware $^{1}$, sob o ponto de vista da experiência deslegitimada, pesquisou adoecidos de fadiga crônica, uma condição debilitante, de etiologia desconhecida pela biomedicina, que expõe os sofredores a uma experiência persistente, inexplicável, incluindo dores de cabeça, musculares, febre, fraqueza, dificuldades de memória, dores articulares, segundo o Centro de Controle das Doenças Norte-Americano.

A autora aponta que os pesquisadores médicos explicam a fadiga crônica à luz de diferentes teorias. Uma delas recorre ao vírus (retrovírus, entreveros, herpes), outras à disfunção imunológica ou às desordens neurofisiológicas e psicológicas, explicações não consensuais entre os médicos. Ela percorreu os saberes biomédico clínico e o epidemiológico, os estudos sobre as opiniões dos médicos sobre a fadiga, completadas com 
discussões conceituais da deslegitimação no saber antropológico.

Kleimnan ${ }^{8}$, antropólogo médico norte-americano, admite a experiência deslegitimada da mesma forma conceituada por Ware ${ }^{1}$, enquanto Das $^{9}$ foca a ordem social, isto é, expõe as origens do sofrimento, demonstrando como ele é vivido podendo se transformar, através do discurso social, em autorização, ou seja, na legitimação da existência das estruturas de poder, enfatizando, portanto, a produção e a construção social do sofrimento. A tensão no foco do indivíduo ou na sociedade permeia esta última definição.

Ware ${ }^{1}$ selecionou 50 indivíduos em um estudo qualitativo feito em Boston e Brigham, com 350 pessoas portadoras de fadiga crônica. Eles foram entrevistados sobre suas histórias de vida, a experiência da enfermidade, através de perguntas abertas. Nesta investigação concluiu que:

1. A percepção e trivialidade das queixas e das sensações corporais apresentadas pelos adoecidos aos demais geralmente convergem para a pergunta: você está cansado?;

2. Os adoecidos não são levados a sério pelos médicos que se expressam com afirmações: você não aparenta estar doente ou você aparenta estar bem. Todos os adoecidos submeteram-se a testes de laboratório e sua condição não foi organicamente diagnosticada. Os médicos pressupõem que estão diante da ausência da doença observável ou de lesão que afastam, no saber médico, a existência da patologia. Para eles, não sendo física, a fadiga envolve algum distúrbio psicológico, considerando irreal os sintomas relatados pelos adoecidos;

3. A natureza psicológica ou psicossomática da fadiga crônica é contestada pelos adoecidos que não se admitem deprimidos, mas fisicamente doentes, cujos sintomas, esperam ser aliviados pela Medicina. Se não puderem ser aliviados, atendidos ou diagnosticados, eles continuam enfrentando as implicações de não estarem acometidos de uma desordem real. Continuam demandando a legitimidade da Medicina para a experiência física e moral que os afligem;

4. Os entrevistados procuraram médicos e mais médicos em busca de diagnóstico, vivendo a incerteza existencial. Outros se envergonharam de sua condição ou do erro sobre a natureza da realidade percebida;

5. A ambiguidade e incerteza geram retraimento e manutenção do segredo da condição, pelos adoecidos, dificultando compartilhá-la com os demais. Não é infrequente a afirmação seria melhor que fosse câncer, admitiu um entrevistado.
Netteleton ${ }^{10}$ destaca que os temas da moralidade, caos e ambivalência permeiam as experiências deslegitimadas, tão prenhes de incertezas, admitindo-as mais presentes e intensas na vida das sociedades pós-industriais. Entretanto, acrescenta-se que os sofrimentos e adoecimentos sempre suscitam indagações e explicações dos adoecidos sobre o porquê e sobre o fato de acometer a própria pessoa que insiste na busca de respostas. Se estas perguntas não são respondidas e se os adoecidos são deslegitimados em seus sofrimentos e adoecimentos físicos e morais, as incertezas e ambivalências se acentuam, afetando a identidade social como pessoa sadia ou não perante a sociedade, a si própria e à Medicina.

\section{Os acometidos de dores crônicas}

As experiências dos sofredores de dores crônicas costumam ser deslegitimadas pela Medicina e legítimas para eles. Estes adoecidos se valem de estratégias para comprovar para os outros a sua dor e o próprio sofrimento. Lembra-se que a definição leiga da enfermidade, segundo Friedson ${ }^{11}$ não se restringe à anormalidade corporal, acrescentando-se a ela critérios sociais, como impossibilidades de cumprir as atividades cotidianas e as obrigações sociais. Kotarba ${ }^{12}$, atento ao processo psicossocial, chamava a atenção para a adoção da carreira de adoecido de dor crônica, que se enquadra, do nosso ponto de vista, na experiência deslegitimada da enfermidade em busca de legitimidade.

A permissão para ser ou estar doente requer a aprovação social da anormalidade comprovada pela Medicina. Além da dependência dos outros e de sua aprovação social, o reconhecimento daquela condição requer socialmente a comprovação médica da doença em muitas situações, exemplificando-se a exigência de atestado médico para justificar as faltas no trabalho e recebimento de benefícios previdenciários, motivados por doenças e para demandar ou obter tratamentos judicializados.

Lima e $\operatorname{Trad}^{13}$ investigaram como os médicos lidam em sua prática com a dor crônica em duas clínicas, situadas, respectivamente, em Salvador e São Paulo, centros de referência para o seu tratamento. Consideram com Good e Good ${ }^{14}$ que a dor crônica se reveste de ambiguidades de sua presença entre o corpo e a mente. As autoras endossam o conceito de racionalidade médica de Madel Luz para compreender a biomedicina, considerando a dor crônica um objeto insubordinado ${ }^{15}$ a esta racionalidade. 
Observaram que a dor é sempre invisível para os médicos que trabalham naquelas clínicas, embora se faça presente nas queixas e experiências dos adoecidos. Nas clínicas da dor, os médicos entrevistados admitem ser ela uma entidade mórbida específica, porém invisível, imponderável e incomensurável. Estas características geram ambiguidades em uma parcela dos médicos, entre acreditar e suspeitar das queixas dos pacientes, enfrentando dificuldades para lidar com este objeto, ancorado na imagem subjetiva. Acrescenta-se que estas ambiguidades também expressam dificuldades deles para lidar com a legitimidade da experiência da dor pelos adoecidos.

Não são todos os médicos que se deixam dominar por estas ambiguidades, à medida que outros admitem a necessidade de acreditar nas queixas dos adoecidos, consideradas verdadeiras. Eles admitem as transformações promovidas pela dor no sujeito, nas estruturas do sistema nervoso, nas mudanças emocionais, comportamentais, relacionais e psicológicas, acreditando tanto nas experiências da dor percebidas, sentidas e legitimadas pelos pacientes, quanto procuram convencê-los de que é preciso conviver com a dor. Não prometem a cura. Buscam a conversão positiva da dor ${ }^{13}$.

Para torná-la visível e mudar as formas de lidar com a dor na prática clínica, as autoras propuseram romper com os cânones da racionalidade biomédica, sua objetividade, abstração da pessoa e distanciamento, recomendando mudanças nos projetos terapêuticos e na abordagem clínica, tornando-a simultaneamente hermenêutica e biomédica. Endossam a necessidade de valorizar nas clínicas da dor a escuta, a compreensão e a negociação.

Aires ${ }^{16}$ vai além quando reflete sobre o cuidado, não especificamente relacionado à dor crônica, reportando-se à designação da atenção à saúde imediatamente interessada no sentido existencial da experiência do adoecimento físico ou mental, ao lado das práticas de promoção, proteção e recuperação da saúde. Isto significa dar maior atenção ao encontro terapêutico humanizado que extrapola o êxito técnico das intervenções. Sem, contudo, prescindir das técnicas, o autor estabelece o diálogo entre a normatividade morfofuncional das tecnologias médicas com a normatividade de outra ordem, oriunda do mundo da vida, posto por Habermas ${ }^{17}$. Pode-se inferir que esta última normatividade reconhece as experiências legitimadas pelos adoecidos com os adoecimentos e sofrimentos, incluindo a dor crônica e outros sofrimentos físicos e morais.
Outro aspecto importante destacado na pesquisa de Lima e $\operatorname{Trad}^{13}$ é a observação de que, diante das formas de indagação da dor pelos médicos interessados em precisar a sua localização e intensidade para orientar seu diagnóstico, deparou-se com o silêncio dos adoecidos/pacientes, ou seja, com as dificuldades deles de manifestarem a dor e de localizá-la.

Estamos, portanto, diante de formas diferentes de identificar e de comunicar a dor, à medida que ela expressa sentimentos e maneiras de expressá-la, sempre regidos pelos códigos culturais. Enquanto a medicina necessita descrevê-la, localizá-la e comprová-la, os adoecidos, sempre inscritos e diferenciados social e culturalmente, dispõem de formas próprias de comunicar e de expressar a dor que necessitam ser compreendidas e investigadas. O próprio silêncio dos adoecidos na situação de uma consulta médica, observado pelas autoras, não sugere a inexistência da experiência com a dor, mas a disparidade entre a forma imposta pela Medicina para identificá-la, comprová-la e localizá-la, e a forma de sua expressão pelos adoecidos.

\section{Outras reflexões sobre a dor crônica: deslegitimidade, experiências pessoais e a cultura}

O conhecimento antropológico chama a atenção do conteúdo simbólico da dor. A antropóloga Sarti ${ }^{18}$ admite que a dor manifesta claramente a relação indivíduo e sociedade. $\mathrm{E}$ as formas de senti-la e de expressá-la são sempre regidas por códigos culturais, e a própria dor, como fato humano, constitui-se a partir dos significados conferidos pela coletividade, que sanciona as formas de manifestação dos sentimentos.

Le Breton, antropólogo, psicólogo e sociólogo francês, escreveu um belo livro sobre a dor, situando-a como um fato da existência, uma experiência partilhada que sempre acompanhou o homem. Ele diz que:

A dor está no cerne da relação do indivíduo com o mundo e na experiência acumulada com ele, ultrapassando, portanto, as configurações do signo clínico, postas pela Medicina. Penetra as experiências pessoais prenhes de significação, interpretação e explicações, sempre mediadas pela cultura, pelas relações sociais e subjetividade. A abordagem da antropologia da dor e da enfermidade, como sofrimentos experimentados pelos enfermos, é uma forma de aproximar-se dos adoecidos não ouvidos pela Medicina ${ }^{19}$.

Tal como a Medicina, Le Breton ${ }^{19}$ distingue a dor aguda, que é transitória, da dor crônica, que 
é persistente, como aquela que trava a existência humana, afirmando que:

Ela conhece as intensidades variáveis, indo do pontilhado que destila os seus efeitos penosos e altera o pleno desenvolvimento da vida quotidiana, à continuação da dor, que paralisa a maior parte das atividades sem o reconforto de uma escapatória próxima.

$\mathrm{O}$ autor acrescenta que a dor total, que geralmente acompanha o fim da vida de adoecidos por AIDS:

Marca o momento em que o indivíduo apenas está ligado ao mundo pelo estilhaço de sua única dor, as suas sensações ou sentimentos são submersos por um sofrimento que o envolve e não the deixa tréguas ${ }^{18}$.

Certamente a experiência acumulada com a dor crônica, compondo as queixas permanentes de adoecidos, frequentemente não explicadas e deslegitimadas pela Medicina, comporta sentido e significação para eles, compondo suas experiências vividas onde ela encontra legitimidade, merecendo a atenção dos profissionais de saúde e não somente a recusa ou suspeita de sua existência.

Kleimnan ${ }^{4}$, refletindo sobre a dor crônica, de etiologia incerta, admite sua inscrição nas experiências vividas dos sofredores, considerando que suas formas mutáveis e de significação nos diferentes contextos sociais são capazes de despertar o interesse dos antropólogos.

$\mathrm{O}$ autor considera duas faces da dor crônica: a primeira se refere à construção da intersubjetividade do sofrimento, a partir da reflexão sobre a dor nas sociedades norte-americana e chinesa, onde chama a atenção para a experiência da deslegitimação e da relegitimação. A segunda face remete à interpretação cultural particular da experiência da dor crônica embebida da resistência, capaz de suscitar limitações à interpretação antropológica.

Trabalhando com as narrativas da dor crônica de três pacientes norte-americanos, residentes em Boston, Kleinman ${ }^{4}$ explorou a variedade do sofrimento como experiência moral, demonstrando como a dor emerge nas micropolíticas das relações sociais advindas das pressões sociais mais amplas que impõem resistência nas experiências interpessoais. Comparando estas experiências com a dor crônica de chineses, sobreviventes da Revolução Cultural, Kleimnan ${ }^{20}$ diz que atrás da dor física estava a grandeza do senso de injustiça.

A sugestão do autor de assumir a dor como sofrimento moral, um objeto crucial ao traba- lho etnográfico, suscita descrever os micros contextos sociais estabelecendo as relações entre os planos pessoal e societário. Na compreensão das experiências da dor pela biomedicina ele não descarta a influência do cartesianismo, impondo à medicina a separação das evidências objetivas e subjetivas, que ancoram sua recusa de legitimar as experiências dos adoecidos, remetendo-as ao plano de suas subjetividades.

\section{Experiências legitimadas ou não com a pressão alta}

A hipertensão arterial sistêmica dispõe de diagnóstico médico, sendo considerada patologia pelo saber biomédico, enquanto as experiências dos adoecidos comportam ambiguidades, incluindo legitimação e deslegitimação da condição de ser ou não considerado doente diagnosticado.

Do ponto de vista biomédico a hipertensão é doença crônica multifatorial, de etiologia desconhecida, grave, incurável, assintomática e de risco para outras enfermidades renais, cardiovasculares e cerebrovasculares. Os médicos advertem na sua prática clínica ser ela doença silenciosa, invisível, grave e perigosa, categorias parcialmente endossadas por meus entrevistados, homens e mulheres, somando trinta e sete pessoas, diagnosticadas da doença, oriundas das classes trabalhadoras que tive oportunidade de entrevistar em uma pesquisa, realizada na cidade de Amparo, Estado de São Paulo ${ }^{21}$.

Este estudo ancorou-se nas ciências sociais (sociologia e antropologia), articulando representações e experiência com o corpo, saúde, doença e cuidado em torno da pressão alta (expressão do senso comum), através de abordagem multidisciplinar capaz de apreender as múltiplas dimensões: individual e coletiva; objetiva e subjetiva; material e imaterial, micro e macro analíticos, enquanto componentes de realidades múltiplas e plurais.

Sem reproduzir todos os resultados obtidos nesta pesquisa que não foi exclusiva sobre a legitimidade/deslegitimidade nota-se que os adoecidos reproduzem os discursos médicos nas representações quanto à gravidade e perigo da enfermidade, sempre comprovados nas experiências próprias (atuais ou pregressas), de parentes ou amigos com o derrame cerebral ou com o infarto do miocárdio. Discordam deles que ela seja "silenciosa", à medida que encontram legitimidade nas suas experiências e sensações corporais, sempre desqualificadas e não reconhecidas pelos médicos, que 
a consideram doença assintomática. Estas sensações podem se exacerbar quando a doença rompe seu silêncio provocando desconfortos físicos; o derrame cerebral ou o infarto do miocárdio.

Como doença diagnosticada pela medicina uma parte dos entrevistados não a considera doença e não assumem a identidade de ser hipertensos e doentes. Neste sentido a experiência vivida com o próprio corpo, mediante a ausência dos sintomas e a possibilidade de manter as atividades e as obrigações sociais deslegitima a enfermidade medicamente diagnosticada e a condição de ser doente e portador da enfermidade.

Observa-se, também, a ressignificação da categoria hipertenso no senso comum, equivalente ao "nervoso" interpretado, em uma de suas dimensões, como alguém agitado contraposto à pessoa calma e equilibrada, que são qualidades morais altamente valorizadas como formas de ser e de estar no mundo, de sociabilidade, de colocar-se nas relações sociais e de responder e de reagir às aflições da vida.

Acrescenta, ainda, a significação da pressão alta no senso comum como uma condição passageira e repentina, explicada pelo movimento do sangue no corpo e não como uma condição duradoura, permanente e crônica, como quer a biomedicina, à medida que esta significação contraria as experiências vividas, percebidas e legitimadas pelos adoecidos. Estas referências, prenhes de significação acompanham as experiências legitimadas com a enfermidade para muitos entrevistados daquela pesquisa.

Selecionamos nesta exposição somente os conteúdos de dois estudos de casos, dos quatro componentes da análise da investigação, para elucidar a discussão proposta neste ensaio. O primeiro inclui a recusa de Francisco (nome fictício) de ser classificado hipertenso pelos médicos e profissionais de saúde, julgando-se moralmente correto (faço tudo certinho, nas suas palavras) pelo fato de seguir as orientações médicas para controlar a doença e de tê-la efetivamente controlada, sugerindo-lhe sua cura.

Isto se completa com as suas concepções de saúde (ausência de sintomas; disposição para trabalhar e de cumprir as obrigações rotineiras), compartilhadas com seu grupo social, que lhes facultam conduzir normalmente a vida e pelo fato de não se auto-identificar-se nervoso e de não apresentar e perceber as mudanças corporais associadas à sua compreensão da pressão alta. Sua experiência, legítima para ele, contraria, portanto, o fato de ser classificado doente pelos profissionais de saúde.
Nas suas palavras:

Tem hora que eu penso que sou hipertenso e depois pergunto, como eu sou hipertenso? O médico falou para eu tomar o remédio certinho e eu estou tomando. Minha pressão não é alta e nunca chegou a 18 e 20, como a de minha mulher. Será que é porque eu me cuido e faço tudo os que os médicos mandam? Como tudo certinho, não como coisa salgada, não bebo, não fumo. Achei meio grave, assustei. Porém na minha ficha eu sou hipertenso.

Nem todos os casos por mim analisados naquele estudo foram iguais ao de Francisco. Alguns adoecidos endossavam as interpretações médicas, os diagnósticos e as prescrições e outros demandavam maior atenção dos médicos para os sofrimentos físicos e morais, que não exclusivamente a hipertensão.

O segundo estudo de caso de Luciana (nome fictício) exemplifica este último aspecto. Diagnosticada de hipertenção arterial sistêmica aos trinta e um anos de idade, deslegitimou este diagnóstico, julgando-se muito jovem, sadia e disposta para trabalhar como faxineira, acreditando ser a doença própria do envelhecimento, associada ao nervoso e aos comportamentos alimentares, explicações compartilhadas com o seu grupo social sobre a gênese da enfermidade. Apesar da história familiar de hipertensão desconsiderou a interpretação médica sobre a importância da hereditariedade dentre os múltiplos fatores associados à etiologia da doença e não observou as prescrições médicas, até o momento em que, aos quarenta e oito anos, sofreu enfarto do miocárdio que a levou à cirurgia cardíaca.

Luciana omitiu nas primeiras entrevistas o fato de ser hipertensa, preferindo relatar, detalhadamente, aquela cirurgia, ocorrida há dez anos e os atuais sofrimentos físicos e morais que a afligem em torno das dores no peito e nas costas, dos problemas vaginais, de tireoide, do nervosismo e da perda do filho. Não se desfez do luto desta perda, simbolizado no uso da roupa preta que não dispensa. Frequenta os diferentes tipos de serviços de saúde (pronto socorro e postos de saúde), demandando insistentemente dos médicos exame de RX, que acredita poder comprovar-lhe, objetivamente, os males sentidos, sem que seja atendida por eles.

Ressente-se dos médicos que deslegitimam suas queixas, expressões dos sofrimentos físicos e morais, embora a orientem nos tratamentos para a hipertensão, gerenciados por ela com muita flexibilidade, segundo suas interpretações, experiências corporais, conhecimentos do senso comum, mesclados aos biomédicos, fé em Deus, 
recusa ao uso contínuo de remédios e conveniências da vida diária. Luciana mantém a identidade de pessoa nervosa, corroborada por sua rede de relações de amizade e de parentesco. De um lado critica os médicos pelo fato de não atenderem às suas demandas e de não ouvirem suas queixas, de outro julga ser bem atendida por eles, deslegitimando o diagnóstico de hipertensão, julgandose curada desta doença, após a cirurgia cardíaca. Encerra a entrevista com a frase: para mim valeu. Está bom.

É interessante focar a experiência relatada por um médico em sua prática clínica com uma hipertensa e sua reflexão sobre a crise da prática médica, suscitando a necessidade de alterar o cuidado e de estabelecer uma relação mais dialógica com os pacientes. É o caso de Violeta, hipertensa, reportado por Aires ${ }^{16}$, mostrando como as práticas de saúde não respondem às necessidades de saúde dos adoecidos. O autor relata que corriqueiramente Da.Violeta entrava em seu consultório, queixando-se da longa espera. Um dia decidiu mudar o seu atendimento, proporcionando-lhe um novo encontro.

Nas suas palavras:

Hoje farei com Dona Violeta um contato inteiramente diferente. Sim, porque me espantava como podíamos ter repetido tantas vezes aquela mesma cena do encontro (encontro?), como os mesmos desdobramentos, sem nunca dar um passo além. Inclusive do ponto de vista terapêutico, pois era a mesma hipertensa descompensada, aquela que não importa quais drogas, dietas ou exercícios prescrevessem, surgia diante de mim a intervalos regulares. Sempre a mesma hipertensão, o mesmo risco cardiovascular, sempre o mesmo mau humor, sempre a mesma queixa sobre a falta de sentido da longa espera ${ }^{15}$.

Foi perguntando sobre a vida de dona Violeta e não sobre como passou desde a última consulta que Aires foi capaz de acessar outra narrativa sobre a sua condição de imigrante, as dificuldades passadas no novo continente; o sonho de obter uma casa, a luta para obtê-la durante anos e, ao obtê-la, veio a morte do marido. Depois disso, as consultas posteriores continuaram: receitas, dietas e exercícios foram prescritos, mas a relação de cuidado mudou, uma sabedoria prática se instaurou, admite Aires, produzindo mudanças no cuidado e resultados na relação da adoecida com as terapêuticas prescritas.

\section{Conclusão}

Esta exposição permite concluir que dilemas, ambiguidades, conflitos ou acomodações cercam as experiências de algumas doenças de longa duração enquadradas ou não nos diagnósticos médicos como patologias. Partiu-se do pressuposto que estas experiências são legítimas para os adoecidos, garantindo seu status e autoridade em relação ao domínio e à expressão dos sofrimentos que os afligem.

Ao invés de submissão passiva aos diagnósticos e aos cânones dos saberes e prática biomédica, os adoecidos, em torno dos exemplos considerados, movem-se por suas experiências dos adoecimentos e sofrimentos físicos e morais, sempre permeados de ações, significações e interpretações. As experiências destes sofredores refletemse no corpo, nas subjetividades, nas relações sociais, suas identidades de ser ou não doentes, nas estratégias utilizadas diante dos serviços de saúde, sempre configuradas nos diferentes grupos sociais e nos devidos contextos socioculturais.

É bastante pertinente abordar estas experiências deslegitimadas pela biomedicina e o processo de legitimação. A pesquisa etnográfica, onde se dá a escuta, a observação atenta, diálogos, interpretação e a escrita do antropólogo permitem aproximar e compreender aquelas experiências, enquanto a escuta e a dialogia na relação médico/ paciente na prática clínica abre brechas ao afloramento das aflições e experiências aflitivas da vida dos adoecidos, a mudanças no cuidado terapêutico e, principalmente, ao aperfeiçoamento da relação médico/paciente. 


\section{Referências}

1. Ware NC. Suffering and social construction of illness: the deligitimation of illness experience in chronic fatigue syndrome. Med. Anthr. Quartely 1992; 6(4):347361.

2. Kleinman A. The illness narrative: suffering, healing and the human condition. New York: Basic Books; 1988.

3. Good B. Medicine, rationality and experience: an anthropological perspective. Cambridge: Cambridge University Press; 1994.

4. Kleinman A. Pain and resistence. The deligitimation and relegitimation of local world. In: Kleimnan A. Writing at the margin. Discourse between anthropology and medicine. Berkeley: California University Press; 1997. p. 120-146.

5. Bury M. The sociology of chronic illness: a review of research and prospects. Soc. Health \& Ilness 1991; 13(4):451-468.

6. Canesqui AM. Estudos antropológicos sobre os adoecidos crônicos. In: Canesqui AM. Olhares socio-antropológicos sobre os adoecidos crônicos. São Paulo: Editora Fapesp, Hucitec; 2007. p. 9-51.

7. Canesqui AM. Adoecimentos de longa duração: análise da literatura brasileira em seis periódicos de Saúde Coletiva/Saúde Pública. In: Canesqui AM. Adoecimentos e Sofrimentos de Longa Duração. São Paulo: Editora Hucitec; 2013. p. 27-69.

8. Kleinman A. Suffering and its professional transformation. Toward an ethnography of experience. Cult. Med. Psychiatry 1991; 15(3):275-301.

9. Das V. Moral orientation to suffering: legitimation, power and healing. In Chen LC, Kleinman A, Ware N, editors. Health and social change: An international perspective. Cambridge: Harvard University Press; 1994. p. 35-50.

10. Nettleton S. Sociol. Health \& Illness. Cambridge: Polity Press; 1995.

11. Friedson E. Profession of Medicine: a Study of the Sociology Applied Knowledge. New York: Harper Row; 1971.
12. Kotarba J. Chronic Pain: its social dimension. Beverley Hills: Sage; 1983.

13. Lima MAG, Trad LAB. A dor crônica sob o olhar médico: modelo biomédico e prática clínica. Cad Saude Publica 2007; 23(11):2672-2689.

14. Good B, Good MJD. The meaning of symptons: a cultural hermeneutic model for clinical practice. In: Eisenberg L, Kleinman A, editors. The relevance of social science for medicin. Dordrecht: Reidel Publishing Company; 1980. p. 165-196.

15. Lima M, Trad LAB. Dor crônica objeto insubordinado. Hist. Cien. Saúde-Manguinhos 2010; 15(1):117-133.

16. Aires JRCM. O cuidado, os modos de ser (do) humano e as práticas de saúde. Saúde e Soc 2004; 13(3):16-29.

17. Habermas M. Ser e tempo. Petrópolis: Vozes; 1995.

18. Sarti AC. A dor, o indivíduo e a cultura. Saúde e Soc. 2001; 10(1):3-13

19. Le Breton D. Compreender a Dor. Um estudo sobre a relação do homem com a dor física em diversos tempos e em diversas culturas. Alfragide: Estrelapolar; 2007.

20. Kleinman A. Social origins of distress and disease: neurastenia, depression and pain in modern China. New Haven: Yale Universityu Press; 1986.

21. Canesqui AM. "Pressão Alta" no cotidiano: experiências e representações. Rio de Janeiro: Ed Fiocruz; 2015.

Artigo apresentado em 14/06/2017

Aprovado em 01/09/2017

Versão final apresentada em 03/09/2017 